\title{
Correction to: A novel method for alveolar bone grafting assessment in cleft lip and palate patients: cone-beam computed tomography evaluation
}

\author{
Marcin Stasiak $^{1}$ (D) Anna Wojtaszek-Słomińska ${ }^{1} \cdot$ Bogna Racka-Pilszak $^{1}$ (D) \\ Published online: 15 September 2020 \\ (C) Springer-Verlag GmbH Germany, part of Springer Nature 2020
}

Correction to: Clinical Oral Investigations https://doi.org/10.1007/s00784-020-03505-z

In figure 2, the description of the 3rd score has been amended:

From: Thickness of the alveolar bone bridge is more than the labiolingual width of central incisor's root.

To: Thickness of the alveolar bone bridge amounts to at least the labiolingual width of central incisor's root.

Below is the corrected figure 2:

Publisher's note Springer Nature remains neutral with regard to jurisdictional claims in published maps and institutional affiliations.

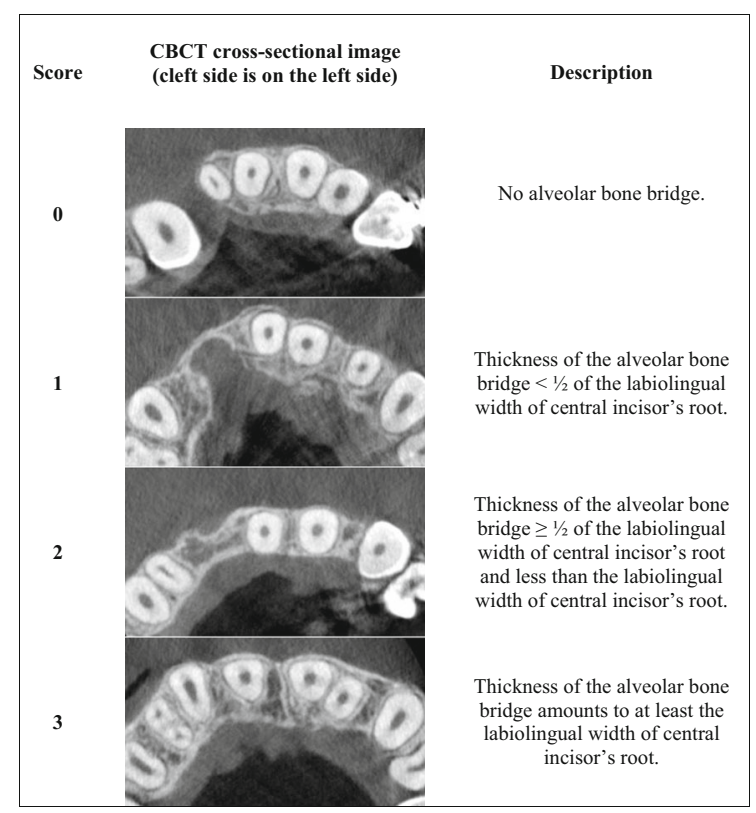

The online version of the original article can be found at https://doi.org/ 10.1007/s00784-020-03505-Z

Marcin Stasiak

marcinstasiak@gumed.edu.pl

1 Department of Orthodontics, Faculty of Medicine, Medical

University of Gdańsk, Aleja Zwycięstwa 42c,

80-210 Gdańsk, Poland 